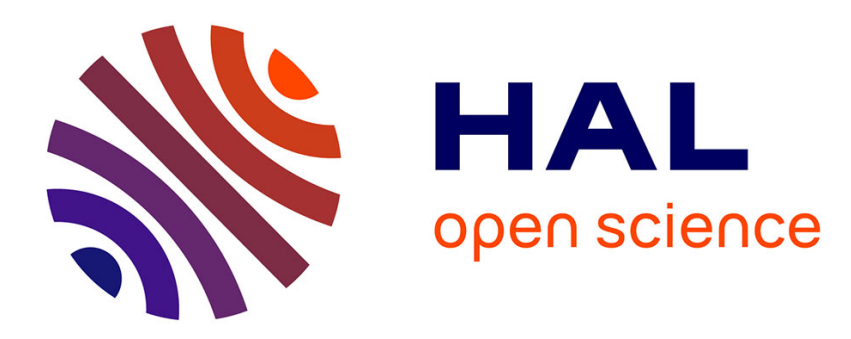

\title{
Size Effect in Crack Shear Strength of Wood
}

S. Morel, G. Valentin

\section{- To cite this version:}

S. Morel, G. Valentin. Size Effect in Crack Shear Strength of Wood. Journal de Physique IV Proceedings, 1996, 06 (C6), pp.C6-385-C6-394. 10.1051/jp4:1996638 . jpa-00254471

\section{HAL Id: jpa-00254471 https://hal.science/jpa-00254471}

Submitted on 1 Jan 1996

HAL is a multi-disciplinary open access archive for the deposit and dissemination of scientific research documents, whether they are published or not. The documents may come from teaching and research institutions in France or abroad, or from public or private research centers.
L'archive ouverte pluridisciplinaire HAL, est destinée au dépôt et à la diffusion de documents scientifiques de niveau recherche, publiés ou non, émanant des établissements d'enseignement et de recherche français ou étrangers, des laboratoires publics ou privés. 


\title{
Size Effect in Crack Shear Strength of Wood
}

\author{
S. Morel and G. Valentin \\ Laboratoire de Rhéologie du Bois de Bordeaux, Domaine de l'Hermitage, BP. 10, 33610 Cestas Gazinet, \\ France
}

\begin{abstract}
It is known for long time that the size of a structure has an important effect on its fracture stress. This phenomenon is called size effect and it seems that it can be attributed to the influence of a damaged zone which develops around the fracture area. Investigations have been made on size effect in shear fracture on two species of wood : Maritime Pine and Norway Spruce. The experimental fracture stresses and energy release rates of geometrically similar specimens of different sizes are analysed according to the size effect law of Bazant. This theoretical model allows an estimation of the evolution of fracture stress and energy release rate in terms of structural size but also an estimation of the dimensional validity areas respectively attributed to non-linear fracture mechanics and to linear elastic fracture mechanics. A comparison of the results was made in order to determine the relative brittleness of Pine and Spruce.
\end{abstract}

\section{INTRODUCTION}

In a building material such as wood, the fracture characteristics obtained in laboratory with small specimens must be applied to structures with large dimension. So, it is necessary to know the evolution of fracture characteristics according to the size of the structure. Indeed, when the volume of a structure increases, the strength generally decreases and it appears that this increase of specimen size produced an increasing brittleness. Several works based on the well-known Weibull's weakest-link theory have been made to describe the size effect in wood [5,7]. This theory governs the size effect in unnotched wood structures failing at the initiation of the first macrocrack from the worst defect (knot, resin pocket...). In this work, this statistical size effect is assumed to play only a minor role. Indeed, the notched fracture specimens used here, show a stable crack growth before the failure. Linear elastic fracture mechanics (LEFM) takes into account the scale effect but is not sufficient to explain the evolution of fracture characteristics. Another approach, "the size effect law" proposed by Bazant [3] and established from LEFM, allows the description of a large part of these phenomena, and mainly the scaling of small to large structures. This method initially proposed for concrete and ceramics [3] can also be applied to wood failure $[1,9]$. In this approach, it is assumed that a damaged zone in front of the crack tip originates some modifications of the stress and displacement fields surrounding this zone. According to the size of the structure, these modifications are more or less important and give rise to modifications of macroscopic behaviour of the structures. In this paper, the size effect law is employed for explaining experimental results of shear fracture in Maritime Pine and Norway Spruce. Geometrically similar specimens of sufficiently different sizes were tested.

\section{SIZE EFFECT LAW.}

In linear elastic fracture mechanics (LEFM), assumption is made that the material is elastic at every point and especially at the crack tip where infinite stresses are analytically obtained. This assumption is never completely fulfilled with real materials. Physically, there always should exist a zone in front of crack tip (fracture process zone) which is in state of progressive damage. In an infinitely large specimen, this zone occupies only an infinitesimal volume of the body; the entire body can be considered as elastic which is the assumption of LEFM. Now, if the fracture process zone occupies an important volume of the 
structure, the stress and displacement fields surrounding this zone are highly perturbed, leading to a behaviour looking like ductility. So, LEFM cannot be used.

Independently of the type of the real toughening mechanism in fracture process zone, the size effect law takes into account this area by assuming an equivalent crack length $\mathbf{a}$ at failure:

$$
a=a_{o}+c
$$

where $a_{o}$ is the initial crack length and $c$ is the elastically equivalent process zone length.

By inserting this equivalent crack length in some equations of LEFM, Bazant obtains an analytic expression of fracture stress as a function of a characteristic dimension $d$ of the structure. The expression (1), called size effect law has been successfully applied to wood in shearing mode [9].

$$
\begin{aligned}
& \tau_{\mathrm{c}}=\frac{\mathrm{B} \cdot \tau_{\mathrm{ref}}}{\sqrt{1+\mathrm{d} / \mathrm{d}_{\mathrm{o}}}} \\
& \text { where } \quad \tau_{\mathrm{c}} \text { is the critical shear stress at failure } \\
& \mathrm{d} \text { is a characteristic dimension of the structure } \\
& \mathrm{B}, \mathrm{d}_{\mathrm{O}} \text {, and } \tau_{\text {ref are empirical constants }}
\end{aligned}
$$

A similar expression (with shear stress replaced by normal stress) has been applied to describe the failure of ceramics, concrete and rocks [3] and wood in opening mode [1]

Moreover, the size effect law allows to determine the evolution of the critical energy release rate $\mathrm{G}_{\text {IIC }}$ as a function of the fracture energy $\mathrm{G}_{\mathrm{IIF}}$ and the characteristic dimension $d$ (equation 2):

$$
\mathrm{G}_{\mathrm{IIC}}=\mathrm{G}_{\mathrm{IF}} \cdot \mathrm{d} /\left(\mathrm{d}+\mathrm{d}_{\mathrm{o}}\right)
$$

with $d_{0}$ is an empirical constant.

\section{EXPERIMENTAL INVESTIGATIONS.}

Investigations have been made on size effect in shear fracture of wood. In order to obtain an evolution of the fracture characteristics, geometrically similar specimens of sufficiently different sizes have been fractured by shear.

\subsection{Material and specimen}

Two species of wood, Maritime Pine (Pinus pinaster Ait) and Norway Spruce (Picea abies L.) have been tested. Average oven dry specific weights were respectively 560 and $390 \mathrm{~kg} / \mathrm{m}^{3}$. Tests were made on Linear Tapered End Notched Flexure specimens (LTENF) displaying a stable crack growth. Six geometrically similar specimens characterised by their height (d) : 25, 37,5, 50, 75, 100 and $200 \mathrm{~mm}$ (Annex 1) have been used.

The thickness (b) was kept equal to $40 \mathrm{~mm}$ for all specimens except the larger specimens ( $\mathrm{d}=200 \mathrm{~mm}$ ) which thickness is equal to $70 \mathrm{~mm}$ for stability reasons.

In each dimension, between 6 to 8 specimens were cut, in the longitudinal-tangential directions, from planks 75 by $225 \mathrm{~mm}$. Moisture content of all specimens was found to fall between 11 and $13 \%$. A chevron notch with a $90^{\circ}$ angle was machined with a band saw and prolonged on $4 \mathrm{~mm}$ with a razor blade as crack starter. The dimensions of LTENF specimens are given in Annex 2. 


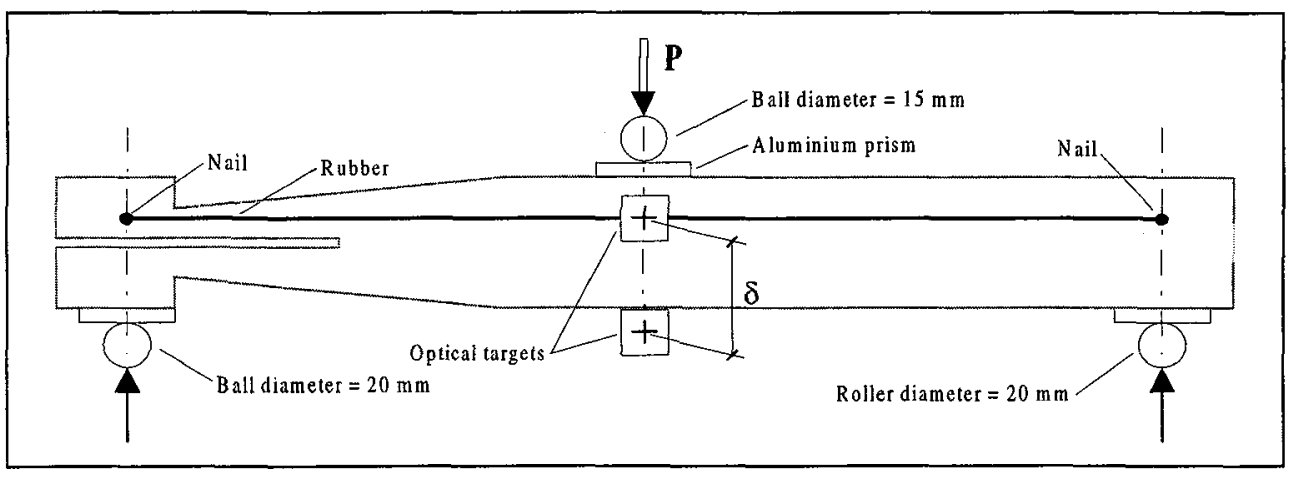

Figure 1 : Test set-up with loading arrangement and optical displacement measurements.

\subsection{Testing}

Tests were made in three points bending at constant cross head displacement rate. Testing arrangements have been described in a proposal by RACOIS [8]. During tests, load-deflection values were continuously recorded. Deflection was measured with an optical extensometer without contact with the specimen. Figure 1 displays the general arrangements with the two targets, one glued at the centre bottom of the specimen, and the other fixed on a rubber string pined by two small nails near the neutral axis of the beam at the straight above its supports. Figure 2-a shows a typical load-displacement curve. On such a curve, the part at quasi constant load is obtained during crack growth. The fracture load $P_{u}$ (ultimate load) is defined as the point at the beginning of the constant load part corresponding to the crack growth.

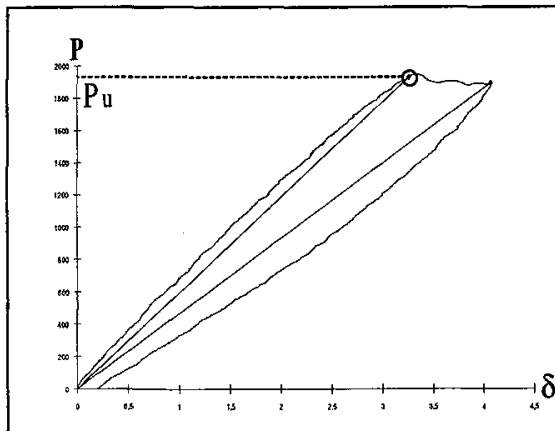

a)

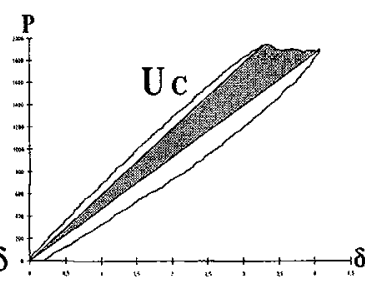

b)

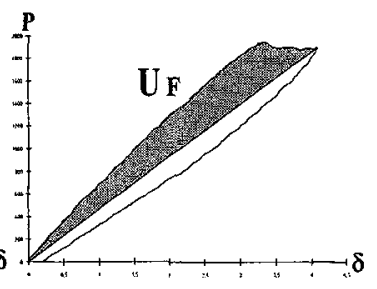

c)

Figure 2 : Typical load-displacement curve of LTENF specimen and calculation of fracture energy.

The critical shearing stress is estimated by :

$$
\tau_{\mathrm{c}}=\frac{3}{4} \cdot \frac{\mathrm{P}_{\mathrm{u}}}{\mathrm{b} \cdot \mathrm{h}}
$$

where : $-P_{u}$ is the ultimate load (fig. 2-a)

- $b$ is the thickness of specimen

$-h$ is the height of the specimen at the end of chevron. 
Moreover, these curves allow to determine the critical energy release rate $G_{\text {IIC }}$ and the fracture energy $G_{\text {IIF }}$ according to the following relations :

$$
\mathrm{G}_{\mathrm{IIC}}=\mathrm{U}_{\mathrm{C}} / \mathrm{A} \quad(4) \quad \mathrm{G}_{\mathrm{IIF}}=\mathrm{U}_{\mathrm{F}} / \mathrm{A}
$$

where : $-U_{C}$ and $U_{F}$ are the energies calculated according to figures 2-b and 2-c

- $A$ is the cracked surface of the specimen.

\subsection{Results.}

The values of $\tau_{c}$ obtained for both species are given for each specimen dimension in figure 3 .

Values of strain energy release rate $\mathrm{G}_{\mathrm{IIC}}$ and fracture energy $\mathrm{G}_{\mathrm{IIF}}$ are given in annex 3 .

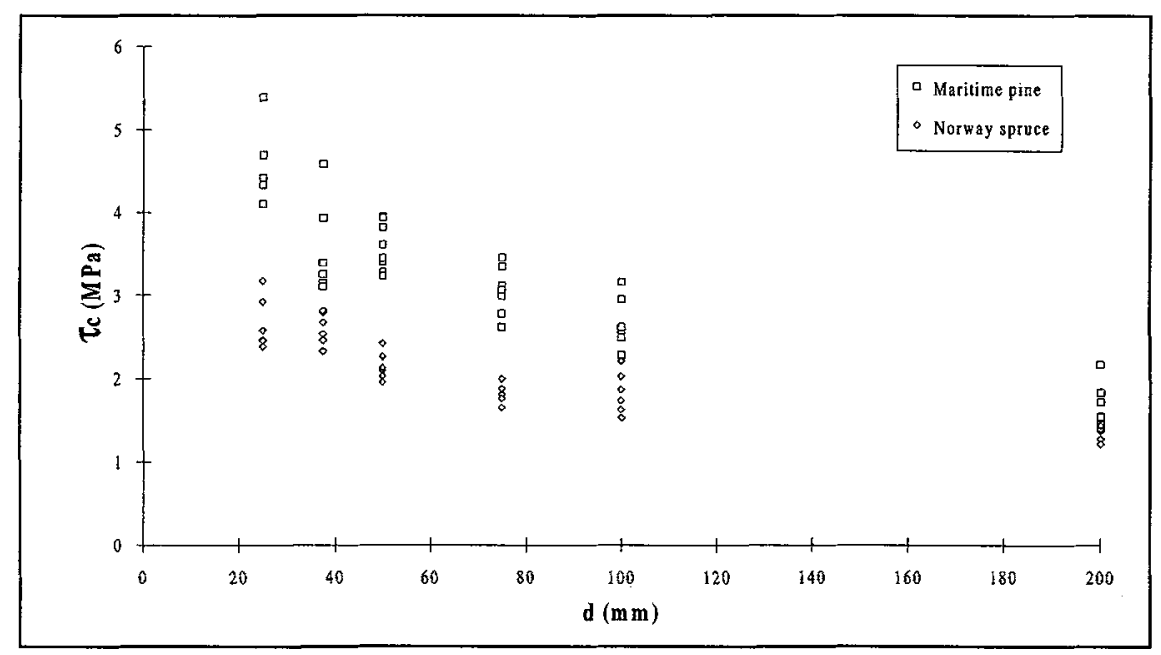

Figure 3 : Critical stresses $\tau_{c}(\mathrm{MPa})$ versus height $\mathrm{d}(\mathrm{mm})$ of specimens.

\section{RESULTS AND DISCUSSION}

\subsection{Results and discussion for Maritime Pine.}

In relation (1), the empirical constants $B, d_{O}$, and $\tau_{\text {ref }}$ can be computed from experimental values (best-fit method).

Taking : $\quad \mathrm{Y}=\left(\tau_{\text {ref }} / \tau_{\mathrm{c}}\right)^{2}, \quad \mathrm{C}=1 / \mathrm{B}^{2}, \quad \mathrm{~A}=1 /\left(\mathrm{B}^{2} \cdot \mathrm{d}_{\mathrm{o}}\right)=\mathrm{C} / \mathrm{d}_{\mathrm{o}}$ relation (1) becomes : $\mathrm{Y}=\mathrm{A} . \mathrm{d}+\mathrm{C}$

In this last relation, $\tau_{\text {ref }}$ and $B$ are linked by the expression $B \cdot \tau_{\text {ref }}=\tau_{\max }$.

So, only $\tau_{\max }$ has a physical meaning.

Choosing a value for $\tau_{\text {ref (for example }} \tau_{\text {ref }}=6 \mathrm{MPa}$ ), a least square method on experimental values $\left(\tau_{\mathrm{c}}, \mathrm{d}\right)$ gives $\tau_{\max }$ and $\mathrm{d}_{\mathrm{o}}$ (Figure 4 ).

The following values are obtained for the size effect law parameter :

$$
\tau_{\max }=6,3 \mathrm{MPa} \text { and } \mathrm{d}_{\mathrm{o}}=21 \mathrm{~mm}
$$

These values are obtained without the biggest specimen $(d=200 \mathrm{~mm})$ because the thickness is $70 \mathrm{~mm}$ instead of $40 \mathrm{~mm}$ and this fact alters the results. 


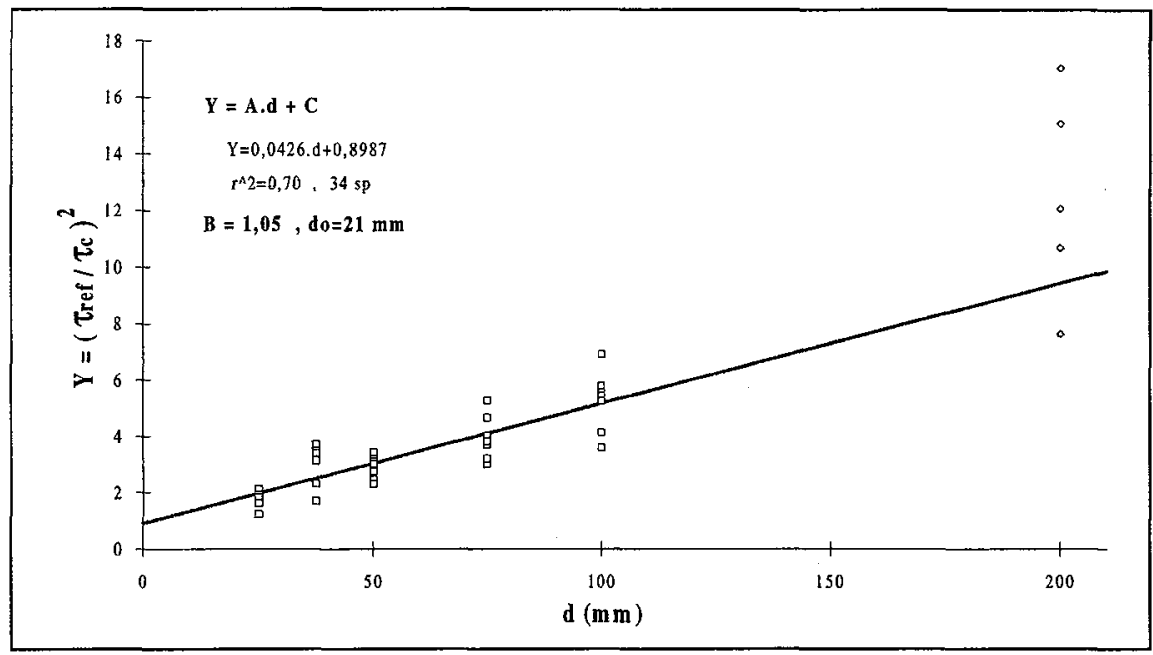

Figure $4:\left(\tau_{\mathrm{ref}} / \tau_{\mathrm{c}}\right)^{2}$ versus height $\mathrm{d}(\mathrm{mm})$ of specimens (Maritime Pine)

Effectively, relation (1) has only been established for homothetic plane specimen (ie identical thickness). However, these experimental stresses are not very far from the best of fit line as can be seen on figure 4 .

Using these values in equation (1) gives a prediction of the size effect in Maritime Pine (Fig.5).

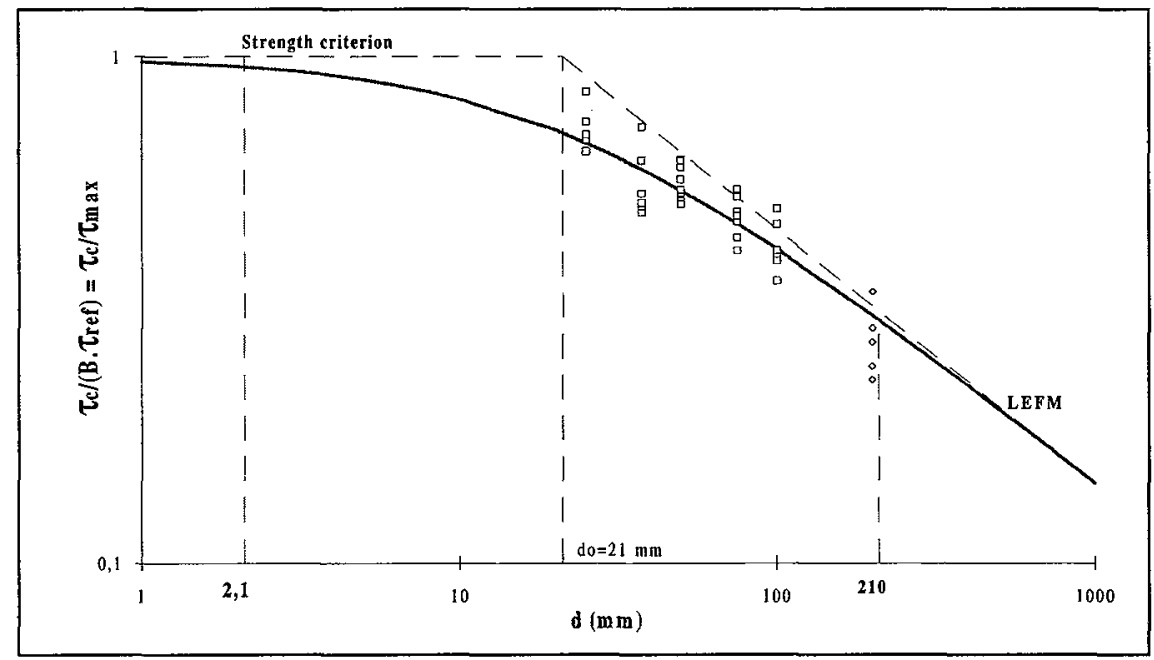

Figure 5 : Size effect on stresses in Maritime Pine : $\tau_{\mathrm{c}} / \tau_{\max }$ versus $\mathrm{d}(\mathrm{mm})\left(\tau_{\max }=6,3 \mathrm{MPa}\right)$

In figure 5, three areas can be distinguished :

- height $d$ of the specimen $<2,1 \mathrm{~mm}$

Theoretical curve becomes asymptotic to an horizontal line. In such structures, there is no size effect, the ultimate load is proportional to a strength criterion. However, these dimensions have not a physical sense for wood material whose heterogeneities dimensions are of this order. 
- height $\mathrm{d}>210 \mathrm{~mm}$

The theoretical curve tends toward a straight line with $-1 / 2$ slope which is the size effect exhibited by LEFM. For these large structures, the fracture process zone can be neglected because it occupies an infinitesimal volume of the body. Therefore, the entire body can be treated as elastic. The stress and displacement fields surrounding the process zone are the asymptotic elastic fields and consequently the failure load can be given by LEFM. Theoretically, these large structures display brittle failures.

$$
-2,1<\mathrm{d}<210 \mathrm{~mm}
$$

These dimensions are generally used in wood design, so they have an economical interest. In such structures, the fracture process zone must be taken into account. The size effect is transitional between strength criterion analysis and LEFM. In this range, the ultimate loads can be determined by non-linear fracture mechanics and relation (1).

The abscissa of intersection point $d_{o}$ between the straight lines representative of LEFM and strength criterion analysis depends on the geometry of the structure and will be used to determine the relative brittleness of Pine and of Spruce.

The main consequence of the size effect law is the influence of the size of the structures on the stress at failure. But theoretically, this size effect is caused by the evolution of the energy release rates according to the size of the specimens.

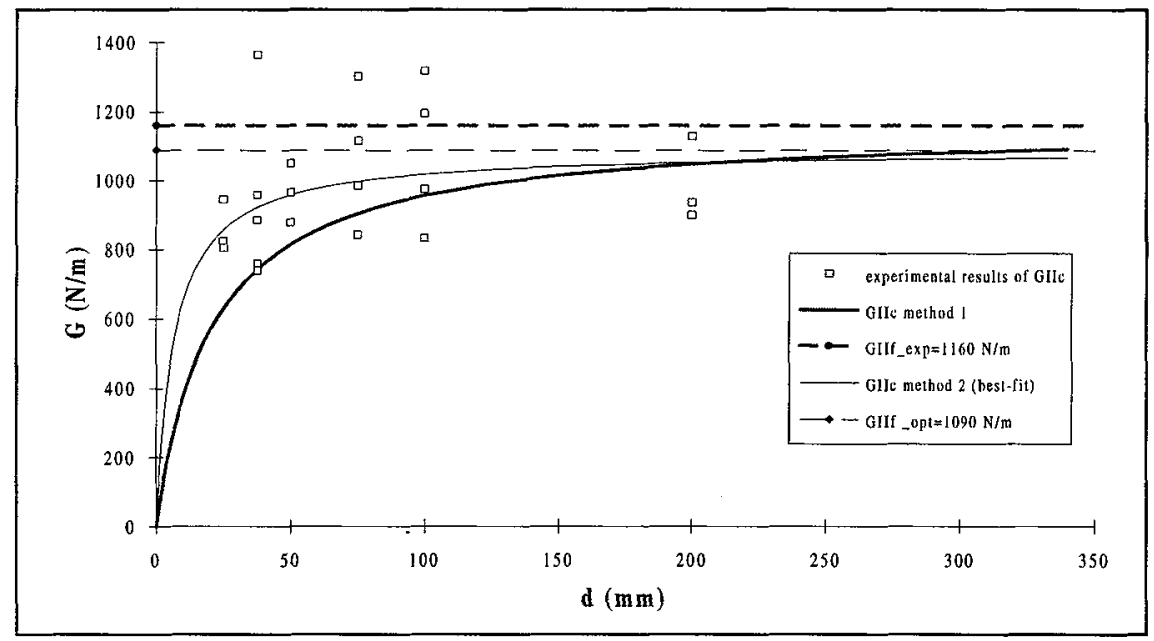

Figure 6 : Size effect on energies in Maritime Pine : $G_{I I C}$ and $G_{I I F}(N / m)$ versus $d(m m)$

Specimens whose crack surfaces deviate from the initial crack plane have not been taken into account in the calculations of the energy release rates $G_{I I C}$. All experimental $G_{I I C}$ and $G_{I I F}$ values are given in Annex 3. Figure 6 displays experimental values of $\mathrm{G}_{\mathrm{IIC}}$ and average value of fracture energy $\mathrm{G}_{\mathrm{IIF}}$ for specimens of various dimensions. $G_{\Pi C}$ appears to be a function of the structural size $d$. The progressive increase of the specimen size produced an increase of the energy release rate up to an asymptotic value equal to the fracture energy $\mathrm{G}_{\mathrm{IIF}}$. Indeed, in an infinitely large specimen, the influence of the process zone on the stress and displacement fields can be neglected. In such structure, the stress and displacement fields are known to be the same for any specimen geometry. In the same way, $\mathrm{G}_{\mathrm{IIF}}$ is defined as the limit of $\mathrm{G}_{\mathrm{IIC}}$ for an infinitely large specimen.

In figure $6, \mathrm{G}_{\text {IIC }}$ is assumed to be predicted by relation (2). In this method (method 1), $\mathrm{G}_{\text {IIC }}$ is computed from $G_{\mathrm{IIF}}=1160 \mathrm{~N} / \mathrm{m}$ (mean of experimental $\mathrm{G}_{\mathrm{IIF}}$ ) and $\mathrm{d}_{\mathrm{o}}=21 \mathrm{~mm}$ computed from relation (1) and the experimental $\tau_{c}$ values. 
In a second method (method 2), a best-fit method is applied directly to experimental G $\mathrm{G}_{\mathrm{IIC}}$ values and relation (2). So, optimum values $\mathrm{G}_{\mathrm{IIF}}=1090 \mathrm{~N} / \mathrm{m}$ and $\mathrm{d}_{\mathrm{o}}=7 \mathrm{~mm}$ are obtained.

The optimum value of $\mathrm{G}_{\mathrm{IIF}}(1090 \mathrm{~N} / \mathrm{m})$ obtained by the method 2 is near to the mean of the experimental $\mathrm{G}_{\mathrm{IIF}}(1160 \mathrm{~N} / \mathrm{m})$.It can be noticed that these mean values are near to the fracture energy obtained by Aicher [2] $\left(\mathrm{G}_{\mathrm{IIF}}=1098 \mathrm{~N} / \mathrm{m}\right)$ on the LTENF specimens of $50 \mathrm{~cm}$ length on a similar wood species. Moreover, the evolution of the energy release rate $\mathrm{G}_{\mathrm{IIC}}$ obtained by method 2 appears more realistic than by method 1 .

However, the difference between the values of $d_{o}$ obtained from the stress analysis $\left(d_{o}=21 \mathrm{~mm}\right)$ and from the energy release rates analysis $\left(d_{o}=7 \mathrm{~mm}\right)$ seems to point out that this parameter must be taken cautiously. This last point is discussed in the next section.

\subsection{Results and discussion for Norway Spruce.}

Parameters $B$ and $d_{o}$ can be obtained according to the method used for Pine. Employing $\tau_{\text {ref }}=4 \mathrm{MPa}$, best-fit method gives : $A=0,0417$ and $C=1,2093$ with correlation coefficient $r^{2}=0,67$ (32sp), and so :

$$
\tau_{\max }=3,6 \mathrm{MPa} \text { and } \mathrm{d}_{\mathrm{o}}=29 \mathrm{~mm}
$$

The predicted size effect of Norway Spruce is given in figure 7 .

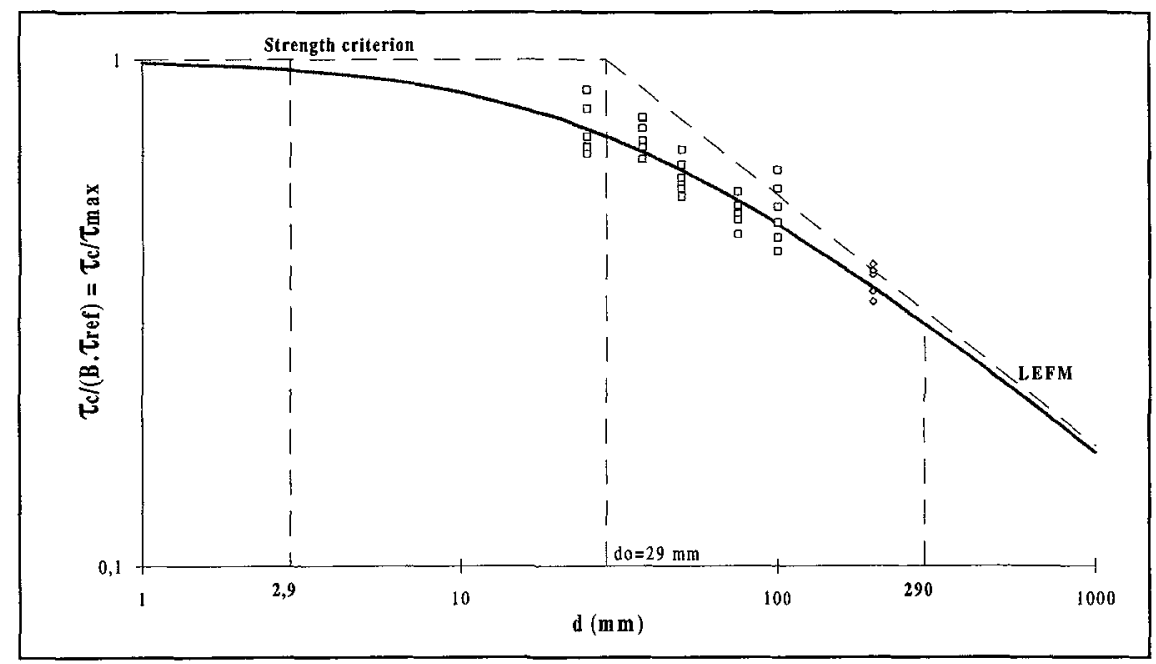

Figure 7 : Size effect on stresses in Norway Spruce : $\tau_{c} / \tau_{\max }$ versus $d(\mathrm{~mm}) \quad\left(\tau_{\max }=3,6 \mathrm{MPa}\right)$

As for Maritime pine, three areas can be distinguished in this figure :

$\begin{array}{ll}-\mathrm{d}<2,9 \mathrm{~mm} & \text { (Strength criterion) } \\ -2,9<\mathrm{d}<290 \mathrm{~mm} & \text { (non-linear fracture mechanics) } \\ -\mathrm{d}>290 \mathrm{~mm} & \text { (LEFM) }\end{array}$

Experimental values of $\mathrm{G}_{\mathrm{IIC}}$ are drawn in figure 8 with average value of $\mathrm{G}_{\mathrm{IIF}}$. Like for Pine, the experimental fracture energies remain constant on the range of dimensions studied $\left(\mathrm{G}_{\mathrm{IIF}}=850 \mathrm{~N} / \mathrm{m} \mathrm{cf}\right.$ Annex 3) and the optimum value of $\mathrm{G}_{\mathrm{IIF}}(800 \mathrm{~N} / \mathrm{m})$ obtained by the method 2 is near to this value. However, energy release rate $\mathrm{G}_{\text {IIC }}$ appears to be a function of the structural size $d$ but it seems that this evolution is less important than for Maritime Pine. Moreover, method 2 (best-fit method) gives a very low value of $d_{o}(4 \mathrm{~mm})$ compared to method 1 in which $d_{o}=29 \mathrm{~mm}$ is deduced from the stress approach. 


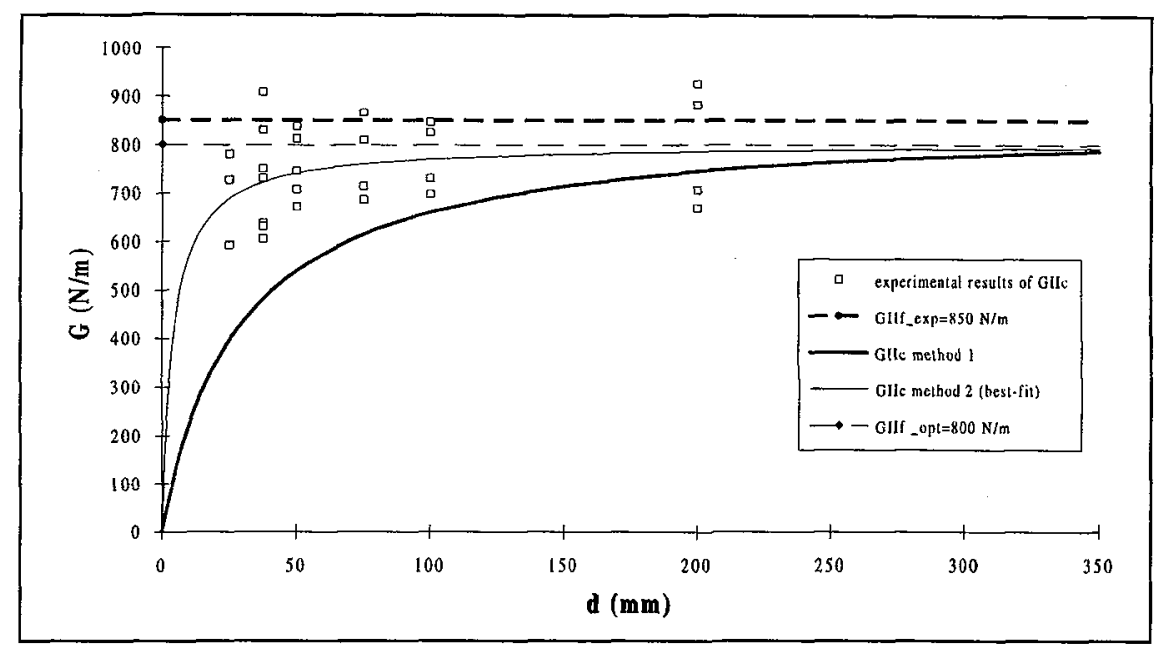

Figure 8 : Size effect on energies in Norway Spruce : $G_{I I C}$ and $G_{I I F}(N / m)$ versus $d(m m)$

This difference seems to point out that energy release rates are overestimated. In computations of energy release rates we ignore the roughness of the crack surface. Indeed, it can be assumed that the real crack surface is more important than the projected surface used in the computations and that the roughness vary according to the specimen size. A study of this result by an other approach, the multifractal scaling [4], is in prospect. On the other hand, the parameter $\mathrm{d}_{\mathrm{o}}$ is calculated according to methods which are different by nature. In calculations from the stresses, the value of $\mathrm{d}_{\mathrm{o}}$ is determined from the stresses corresponding to the starting of the crack growth, when, in calculations from the energy, $d_{o}$ is calculated after the crack propagation.

At last, a previous work [6] has been performed on the effects of varying dimensions on the same fracture specimen but no significant size effect has been shown. In fact, the dimensions range studied (specimen length between 37 and $75 \mathrm{~cm}$ ) was not sufficiently large to show a size effect.

\section{CONCLUSIONS.}

The size effect law displays the characteristic dimension $d_{o}=21 \mathrm{~mm}$ for Pine and $d_{o}=29 \mathrm{~mm}$ for Spruce. The difference between these values $\left(\mathrm{d}_{\mathrm{o}}(\right.$ Pine $)<\mathrm{d}_{\mathrm{o}}$ (Spruce) ) shows that the experimental stresses obtained for Pine are closer to the area of LEFM than the stresses obtained for Spruce. This difference seems to establish that Pine appears more brittle than Spruce. Experimentally it has been noticed that crack speeds were faster in Pine than in Spruce specimens.

The size effect has been explained by the differences between the energy release rates of small and large structures. It can be established that $\mathrm{G}_{\mathrm{IIC}}$ is a function of the structural size $d$. It appears that the progressive increase of specimen size produces an increase of the energy release rate up to the asymptotic value $\mathrm{G}_{\mathrm{IIF}}$.

On the other hand, the fracture energy and the shear fracture stresses of Pine are higher than for Spruce. The anatomical characteristics of both species being the same, the difference between specific weights of Pine $(560 \mathrm{~kg} / \mathrm{m} 3)$ and Spruce $(390 \mathrm{~kg} / \mathrm{m} 3)$ and the intracellular fracture mode can explain the difference of these fracture characteristics.

The study performed from the stresses shows that the knowledge of the size effect law allows an estimation of the evolution of fracture stress and also an estimation of the dimensional validity areas respectively attributed to non-linear fracture mechanics and to linear elastic fracture mechanics. 


\section{References}

[1] Aicher S., 1992. Fracture and size effect law for Spruce and oak in mode I and mixed mode I and II. RILEM TC 133 Meeting, Bordeaux, France.

[2] Aicher S., Gierl M., Klöck W., 1994. A study on mode II specimens for wood with emphasis on fracture energy determination. Otto Graf Journal, Vol 5, pp 11-40.

[3] Bazant P., Kazemi M., 1990. Size effect in fracture of ceramics and its use to determine fracture energy and effective process zone length. Journal of the American Ceramic Society, Vol 73, $\mathrm{N}^{\circ} 7$, pp 1841-1853.

[4] Carpinteri A., Chiaia B., 1995. Multifractal nature of concrete fracture surfaces and size effects on nominal fracture energy. Materials and structures, Vol 28, pp 435-443.

[5] Délisée C., 1987. Variabilité des propriétés mécaniques du Pin Maritime - Effet d'échelle. Thèse de l'Université Bordeaux I.

[6] Kretschmann D., 1995. Effect of varying dimensions on tapered end-notched flexure shear specimen. Wood Science and Technology, Vol 29, pp 287-293.

[7] Madsen B., Buchanan A., 1984. Size effect in timber explained by a modified weakest link theory. IUFRO, Wood Engineering Group, Xalapa.

[8] Racois P., Valentin G., 1993. Proposal of shear specimen for determination of fracture mechanics properties in wood (2nd DRAFT). RILEM TC 133. Lausanne Meeting 1993.

[9] Valentin G., Morel S., 1995. Effet d'échelle et résistance à la fissuration par cisaillement du bois. Actes du 30ème colloque annuel du Groupe Français de Rhéologie, Bordeaux, Volume XIV, $\mathbf{N}^{\circ} 1$, pp 285-294.

\section{Annex}

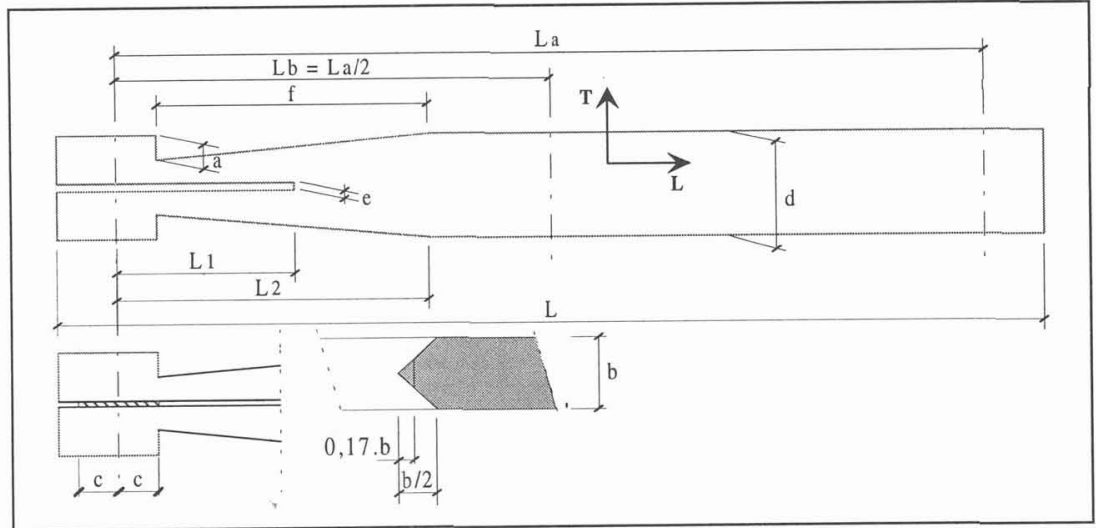

Annex 1 : LTENF specimens.

Annex 2 : Dimensions of LTENF specimens (mm).

\begin{tabular}{|c||c|c|c|c|c|c|c|c|c|}
\hline $\mathbf{d}$ & $\mathbf{L}$ & $\mathbf{L a}$ & $\mathbf{L 1}$ & $\mathbf{L 2}$ & $\mathbf{a}$ & $\mathbf{f}$ & $\mathbf{e}$ & $\mathbf{c}$ & $\mathbf{b}$ \\
\hline \hline $\mathbf{2 5}$ & 250 & 220,5 & 40 & $\mathbf{8 0}$ & 7,5 & 70 & 2 & 10 & 40 \\
$\mathbf{3 7 , 5}$ & 375 & 331 & 60 & 120 & 11 & 105 & 2 & 15 & 40 \\
$\mathbf{5 0}$ & 500 & 441 & 80 & 160,5 & 15 & 140 & 2 & 20 & 40 \\
$\mathbf{7 5}$ & 750 & 662 & 120 & 225 & 22,5 & 210 & 2 & 30 & 40 \\
$\mathbf{1 0 0}$ & 1000 & 882 & 160 & 241 & 30 & 280 & 2 & 40 & 40 \\
$\mathbf{2 0 0}$ & 2000 & 1764 & 320 & 642 & 60 & 560 & 2 & 80 & 70 \\
\hline
\end{tabular}


Annex 3 : Results obtained with Maritime Pine and Norway Spruce.

\begin{tabular}{|c|c|c|c|c|c|c|}
\hline & Maritime & Pine & & Norway & Spruce & \\
\hline d & specimen & GiIr. & $\mathbf{G}_{\mathbf{I r F}}$ & specimen & GIIC. & $\mathbf{G}_{\text {IIF }}$ \\
\hline$(\mathrm{mm})$ & $\mathrm{n}^{\circ}$ & $(\mathrm{N} / \mathrm{m})$ & $(\mathrm{N} / \mathrm{m})$ & $\mathrm{n}^{\circ}$ & $(\mathrm{N} / \mathrm{m})$ & $(\mathrm{N} / \mathrm{m})$ \\
\hline 25 & $\mathrm{p} 25-1$ & 1 & 1 & s25-1 & 780 & 1010 \\
\hline$/ /$ & p25-2 & 830 & 1090 & s25-2 & 1 & 1 \\
\hline$/ /$ & $\mathrm{p} 25-3$ & 810 & 1030 & s $25-3$ & 590 & 730 \\
\hline$/ /$ & p25-4 & 1 & 1 & $s 25-4$ & 1 & 1 \\
\hline$/ /$ & p25-5 & 950 & 1240 & s25-5 & 730 & 890 \\
\hline$/ /$ & p25-6 & 1 & 1 & s25-6 & 1 & 1 \\
\hline $\begin{array}{c}\text { Mean } \\
\operatorname{COV}(\%)\end{array}$ & & $\begin{array}{l}859 \\
8,81\end{array}$ & * & & $\begin{array}{c}700 \\
13,82\end{array}$ & * \\
\hline 37,5 & p37-1 & 960 & $10 \overline{1090}$ & s37-1 & 730 & 840 \\
\hline$/ /$ & p37-2 & 740 & 930 & s37-2 & 750 & 870 \\
\hline$/ /$ & p37-3 & 1 & 1 & s.37-3 & 640 & 730 \\
\hline $1 /$ & p37-4 & 890 & 1060 & s37-4 & 910 & 1060 \\
\hline // & p37-5 & 1360 & 1610 & s37-5 & 630 & 740 \\
\hline /I & p37-6 & 760 & 900 & s37.6 & 830 & 960 \\
\hline$/ /$ & - & - & - & s37-7 & 610 & 690 \\
\hline $\begin{array}{c}\text { Mean } \\
\operatorname{Cov}(\%)\end{array}$ & & $\begin{array}{c}942 \\
26,84\end{array}$ & * & & $\begin{array}{c}728 \\
15,50\end{array}$ & $\begin{array}{l}* \\
*\end{array}$ \\
\hline$=50$ & p50-1 & 1 & 1 & s50-1 & 810 & $\overline{930}$ \\
\hline$/ 1$ & p50-2 & 1050 & 1250 & $s 50-2$ & 670 & 750 \\
\hline$/ /$ & p50-3 & 1 & / & $s 50-3$ & 710 & 810 \\
\hline$/ /$ & p50-4 & 970 & 1120 & s50-4 & 1 & 1 \\
\hline II & p50-5 & 880 & 1030 & s50-5 & 840 & 950 \\
\hline$/ /$ & p50-6 & 970 & 1120 & $s 50-6$ & 750 & 850 \\
\hline$/ 1$ & p50-7 & 1 & 1 & s50-7 & 1 & 1 \\
\hline$/ /$ & p50-8 & 1050 & 1170 & - & - & - \\
\hline Mean & & 983 & $*$ & & 756 & * \\
\hline $\operatorname{Cov}(\%)$ & & 7,30 & $*$ & & 9,18 & $*$ \\
\hline 75 & p75-1 & 990 & 11110 & s75-1 & 720 & 790 \\
\hline$/ /$ & p75-2 & 840 & 960 & s75-2 & 1 & 1 \\
\hline$/ /$ & p75-3 & 1300 & 1540 & s75-3 & 690 & 770 \\
\hline /I & p75-4 & 1 & I & s75-4 & 1 & 1 \\
\hline$/ 1$ & p75-5 & 1120 & 1270 & s75-5 & 870 & 970 \\
\hline$/ /$ & p $75-6$ & 1 & I & $s 75-6$ & 810 & 870 \\
\hline $1 /$ & p $75-7$ & 1 & I & - & - & - \\
\hline Mean & & 1063 & * & & 770 & * \\
\hline $\operatorname{cov}(\%)$ & & 18,33 & * & & 10,80 & $*$ \\
\hline 100 & p100-1 & 840 & 970 & s100-1 & 730 & 800 \\
\hline$/ /$ & p100-2 & 980 & 1070 & s100-2 & 850 & 930 \\
\hline /1 & p100-3 & 1200 & 1390 & s100-3 & 830 & 920 \\
\hline$/ 1$ & p $100-4$ & I & I & $5100-4$ & 1 & 1 \\
\hline$/ /$ & p100-5 & 1 & 1 & s $100-5$ & 700 & 760 \\
\hline$/ /$ & p100-6 & 1320 & 1480 & $s 100-6$ & I & I \\
\hline$/ /$ & p100-7 & 1 & 1 & - & - & - \\
\hline Mean & & 1081 & $*$ & & 776 & $*$ \\
\hline $\operatorname{COV}(\%)$ & & 20,04 & $*$ & & 9,26 & $*$ \\
\hline 200 & $\mathrm{p} 200-1$ & 900 & 1020 & $s 200-1$ & 710 & $\overline{770}$ \\
\hline$/ 1$ & p200-2 & 1130 & 1290 & $\mathrm{~s} 200-2$ & 1 & 1 \\
\hline$/ /$ & p200-3 & 840 & 1060 & $\mathrm{~s} 200-3$ & 880 & 940 \\
\hline$/ /$ & p200-4 & 1 & 1 & $s 200-4$ & 670 & 700 \\
\hline$/ /$ & p200-5 & 1 & I & s200-5 & 930 & 1010 \\
\hline 11 & - & - & - & s200-6 & 1 & 1 \\
\hline $\begin{array}{c}\text { Mean } \\
\text { COV (\%) }\end{array}$ & & $\begin{array}{c}990 \\
12,42\end{array}$ & $\begin{array}{l}1160 \\
16,50\end{array}$ & & $\begin{array}{c}796 \\
15,98\end{array}$ & $\begin{array}{c}850 \\
12,37\end{array}$ \\
\hline
\end{tabular}

